\section{Middle Age mortality}

W.F. Bynum

The Black Death: Natural and Human

Disaster in Medieval Europe.

By Robert S. Gottfried.

Robert Hall/Macmillan: 1983.

Pp.203. \$16.95, £9.95.

LEGIONNAIRES' disease, lassa fever, typhoid: despite our immunizations and antibiotics we remain psychologically vulnerable to epidemic disease, particularly if it is exotic or unexpected, or its cause is obscure. It could be, Robert Gottfried seems to suggest, that this nagging anxiety is just one more legacy of the Black Death, which he describes as "the greatest biological-environmental event in history'.

Certainly the demographic, economic, social, political and cultural consequences of the European experience with plague during the three centuries following the Black Death of the 1340s were vast, even if Gottfried sometimes reaches for the hyperboles a bit too casually. Nevertheless, this latest biography of Yersinia pestis has much to recommend it.

There is, of course, no dearth of historical analysis of plague, most sweepingly perhaps as part of William McNeill's ambitious examination of the interplay of disease and history, Plagues and Peoples (Blackwell, 1976). Gottfried writes from the same ecological perspective as McNeill, and much the best part of his own work is the use he makes of recent research on climate, agricultural productivity, and population density in thirteenth and early fourteenth-century Europe.

He shows that even before the coming of plague, the medieval economy and social structure had been seriously affected by a century of cooler, wet weather and disastrous harvests. This provides a fascinating backdrop to his central chapters chronicling the beginnings, spread and immediate effects of the Black Death. While Gottfried is not so evocative as Philip Ziegler (The Black Death, Collins, 1969), his narrative holds the attention and his sober analyses of mortality estimates and social and psychological effects make compelling reading. Throughout Europe and the Middle East, the figures varied but the basic pattern was the same: $30-40 \%$ mortality in Pisa, as high as $60 \%$ in the villages surrounding Bury St Edmunds, "only" $10 \%$ in Nuremberg. In a sense, the wonder is that outbreaks of millenarianism, flagellation, or Jewish persecution were not more common than they were.

In another sense, though, the European experience with the Black Death demonstrates how resilient human beings can be, and there is a danger of reading too much back into this horrific episode and the repeated outbreaks of plague during the next centuries. Gottfried is aware of this problem and reminds his readers occasionally that not all of European history between 1347 and 1666 can be seen in terms of the mentality and depopulation engendered by plague.

Too often, however, the caveats get lost in his rhetoric, as the plague is invoked as ' $a$ ' cause, or even 'the' cause, of virtually every major scientific, social, political or cultural transformation during the period. A good example of this tendency is his chapter entitled 'The Stirrings of Modern Medicine', in which a whole series of professional, educational and intellectual changes in medicine are associated with the Black Death: 'Before the Black Death. . . After the Black Death. . . .' These phrases

\section{Diet and decline}

\section{Alex Comfort}

\section{Handbook of Nutrition, Health} and Ageing.

By Donald M. Watkin.

Noyes Publications, Park Ridge, New

Jersey: 1983. Pp.290. \$32.

A HANDBOOK is a comprehensive practical summary. So a handbook of nutrition, health and ageing might be expected to consist of more than one volume. At the same time, while public pressure and some dedicated missionary activity have not yet succeeded in raising geriatric medicine in the United States to European levels, or in mobilizing proper social services to support it, they have persuaded publishers to add the word "ageing" to as many titles as possible - often with little change in the matter which follows.

This, unfortunately, is the case with Dr Watkin's book. Nutrition is a hard subject to address because, as in economics, the experts and the results are often at odds. What Dr Watkin has compiled is in essence a double book. The first section is an elementary summary of nutrition, the second a useful though short survey of Federal nutrition programmes. Over these, the issue of ageing has been scattered, as from a pepper-grinder: one is glad to see it there, but sorry that existing research in this field has not been more systematically addressed.

I find this extraordinary, because, as Dr Watkin points out, caloric restriction is at the moment the only experimental intervention which appears to modify the rate of senescence in mammals. Other nutritional maxims attacking excessive consumption of fats, unbalanced diets and alcohol are aimed at causes of shortening life, the substance of these has changed remarkably little since Cornaro or Hufeland, though Dr Watkin presents them in more fashionable dress. In a recur and Gottfried slips casually into this mode, sometimes sacrificing historical subtlety on the altar of dramatic effect. Consequently, the book requires thoughtful reading. But it is decidedly worth reading as a stimulating introduction to its topic and a cogent synthesis of modern scholarship on plague. That scholarship itself can be approached by Gottfried's helpful 'Bibliographical Essay' (pp. 187-194), the extent of which testifies to the continuing historical preoccupation with study of the impact of epidemic disease on our ancestors and thereby on ourselves.

Dr. W.F. Bynum is at the Wellcome Institute for the History of Medicine, London.

section headed "State of the Art", Watkin cites McCay, mentions a couple of the wide-ranging and important papers by Ross and then reports his failure to find any furthur relevant studies on Medlars hardly surprising, since the focus in investigating the mechanism of the McCay effect has shifted to neuroamines, immunology and other areas: the "state of the art" seems to have slipped through Dr Watkin's net.

In the area of health-maintenance he does rather better; the bibliography would be useful if it were alphabetically arranged. Dr Watkin has the conviction - probably correct - that much could be done through nutrition research to reduce agelinked disability (an attack on alcohol and cigarettes would certainly do this) but the two brief sections on the "State of the Art" (12 pages) and "Putting it All Together" (10 pages) hardly live up to their promise. They give the impression that the Federal programmes which Watkin summarizes, and which are admirable as far as they go, have the matter under control - which they haven't. Not only has nutrition research in preventive medicine a sizeable Augean stable to cleanse before it reaches convincing unanimity: with malnutrition due to poverty and cutbacks in social programmes a growing problem in Reaganomic America, the book gives an over-rosy picture of a contentious, disorderly and partisan field of investigation - one where what science there is, is frustrated by politics.

A comprehensive review of nutrition in relation to gerontology and geriatrics remains to be written. A comprehensive review of nutrition and health in the underfed could now be written from abundant experience, unfortunately. A comprehensive review of nutrition in the overfed and injudiciously fed is badly needed but its time has not yet come. America contains both populations, and both of them are ageing.

Alex Comfort is an Adjunct Professor at the University of California, Los Angeles. 